\title{
Disentangling direct and indirect effects of local temperature on abundance of mountain birds and implications for understanding global change impacts
}

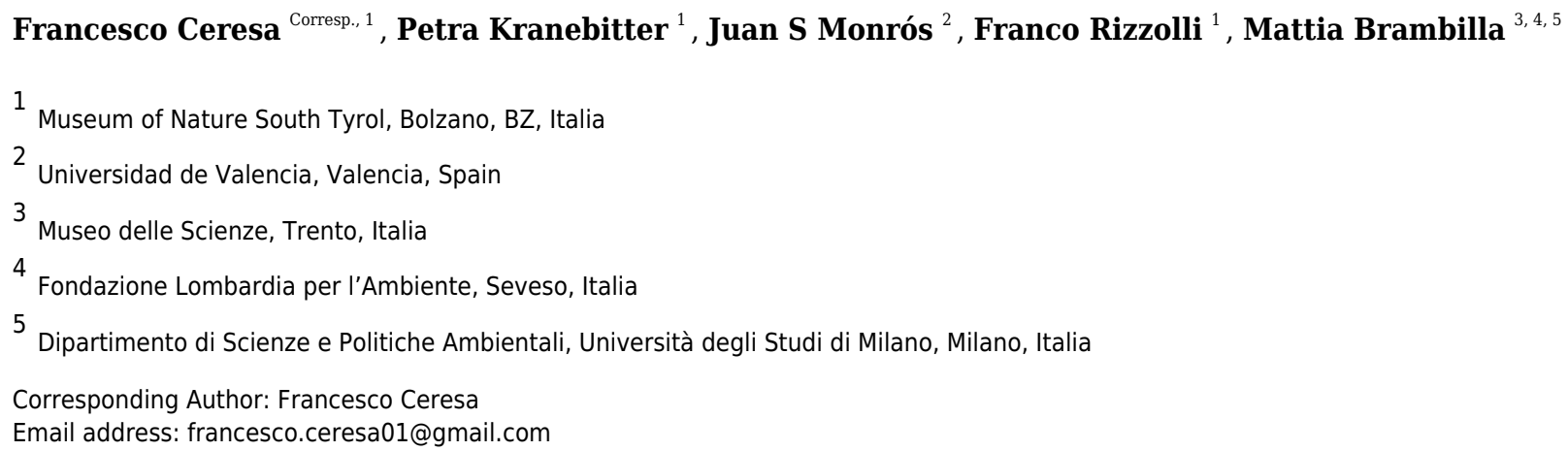

Unravelling the environmental factors driving species distribution and abundance is crucial in ecology and conservation. Both climatic and land cover factors are often used to describe species distribution/abundance, but their interrelations have been scarcely investigated. Climatic factors may indeed affect species both directly and indirectly, e.g. by influencing vegetation structure and composition. We aimed to disentangle the direct and indirect effects (via vegetation) of local temperature on bird abundance across a wide elevational gradient in the European Alps, ranging from montane forests to high-elevation open areas. In year 2018, we surveyed birds by using point counts and collected fine-scale land cover and temperature data from 109 sampling points. We used structural equation modelling to estimate direct and indirect effects of local climate on bird abundance. We obtained a sufficient sample for 15 species, characterized by a broad variety of ecological requirements. For all species we found a significant indirect effect of local temperatures via vegetation on bird abundance. Direct effects of temperature were less common and were observed in seven woodland/shrubland species, including only mountain generalists; in these cases, local temperatures showed a positive effect, suggesting that on average our study area is likely colder than the thermal optimum of those species. The generalized occurrence of indirect temperature effects within our species set demonstrates the importance of considering both climate and land cover changes to obtain more reliable predictions of future species distribution/abundance. In fact, many species may be largely tracking suitable habitat rather than thermal niches, especially among homeotherm organisms like birds. 
Disentangling direct and indirect effects of local temperature on abundance of mountain birds and implications for understanding global change impacts

Francesco Ceresa $^{1 *}$, Petra Kranebitter ${ }^{1}$, Juan S. Monrós ${ }^{2}$, Franco Rizzolli ${ }^{1}$ and Mattia Brambilla $3,4,5$

${ }^{1}$ Museum of Nature South Tyrol, Bolzano, Italy

${ }^{2}$ Institute Cavanilles of Biodiversity and Evolutionary Biology, University of Valencia, Paterna (Valencia), Spain

${ }^{3}$ Museo delle Scienze, Sezione Zoologia dei Vertebrati, Trento, Italy

${ }^{4}$ Fondazione Lombardia per l'Ambiente, Settore Biodiversità e Aree protette, Milano, Italy

${ }^{5}$ Università degli Studi di Milano, Dipartimento di Scienze e Politiche Ambientali, Milano, Italy

*Corresponding author; http://orcid.org/0000-0003-4443-9667; francesco.ceresa01@gmail.com; tel. 00393467285401 


\section{Abstract}

2

3 Unravelling the environmental factors driving species distribution and abundance is crucial in

4 ecology and conservation. Both climatic and land cover factors are often used to describe species

5 distribution/abundance, but their interrelations have been scarcely investigated. Climatic factors

6 may indeed affect species both directly and indirectly, e.g. by influencing vegetation structure

7 and composition. We aimed to disentangle the direct and indirect effects (via vegetation) of local

8 temperature on bird abundance across a wide elevational gradient in the European Alps, ranging

9 from montane forests to high-elevation open areas. In year 2018, we surveyed birds by using

10 point counts and collected fine-scale land cover and temperature data from 109 sampling points.

11 We used structural equation modelling to estimate direct and indirect effects of local climate on

12 bird abundance. We obtained a sufficient sample for 15 species, characterized by a broad variety

13 of ecological requirements. For all species we found a significant indirect effect of local

14 temperatures via vegetation on bird abundance. Direct effects of temperature were less common

15 and were observed in seven woodland/shrubland species, including only mountain generalists; in

16 these cases, local temperatures showed a positive effect, suggesting that on average our study

17 area is likely colder than the thermal optimum of those species. The generalized occurrence of

18 indirect temperature effects within our species set demonstrates the importance of considering

19 both climate and land cover changes to obtain more reliable predictions of future species 
20 distribution/abundance. In fact, many species may be largely tracking suitable habitat rather than

21 thermal niches, especially among homeotherm organisms like birds.

22

23

24

25

26

27

28

29

Keywords: elevational gradient; bird ecology; thermal niche; European Alps; high-elevation species

\section{Introduction}

Climate and land-use/land-cover strongly affect the distribution and abundance of species and many ecosystems functions (e.g. Sala et al. 2000). To correctly understand the impact of global change, and in particular of climate and land-use modification, unravelling the environmental factors determining species distribution and abundance is crucial (Rodríguez et al. 2007; Péron and Altwegg 2015; Engler et al. 2017). While this is a key issue across ecosystems and realms (Mantyka-Pringle et al. 2012), for some groups, such as birds (e.g. Jongsomjit et al. 2013), and some environments, such as mountains (Dirnböck et al. 2011), disentangling those effects is of utmost importance to address urgent conservation challenges (Chamberlain et al. 2013).

Unfortunately, studies explicitly addressing both land-use and climate change effects are relatively scarce (e.g., Pearce-Higgins et al. 2015), and there are few studies that have really tried to quantitatively partition the interactive effects of climate and land-use on target species. Mountains are characterized by a strong variation across short distances of abiotic factors such as temperature, precipitation, atmospheric pressure, slope and exposure. This leads to a high variety of habitats and species occurring within relatively small areas and stratified across 
43 elevational gradients (Körner and Oshawa 2006; Cadena et al. 2012). This often results also in

44 patchily distributions of species that are strictly connected to very specific elevation ranges, and

45

46

47

also in high endemism levels (Ruggiero and Hawkins 2008; Cadena et al. 2012). Mountain

ecosystems are consequently extremely valuable in terms of biodiversity and conservation

(Myers et al. 2000; Körner and Oshawa 2006; Boyle and Martin 2015), but species specialist of those ecosystems are highly threatened by climate change (e.g., Goodenough and Hart 2013;

Brambilla et al. 2017; de Gabriel Hernando et al. 2021), because of their adaptation to local conditions (Cheviron and Brumfield 2012). Among birds, species distribution/abundance along elevational gradients have been investigated in several studies (e.g., Chamberlain et al. 2016;

Frey et al. 2016; Elsen et al. 2017; Jähnig et al. 2020), considering factors such as local climate, vegetation characteristics and topography as explanatory variables. Studies on factors driving occurrence or abundance along environmental gradients provide highly valuable information, but the interplay between climate and vegetation in determining mountain bird distribution/abundance is still unclear. In fact, these factors are usually considered independently in data analyses, without estimating the indirect effects deriving from the causal relationships between climate and vegetation (but see Duclos et al. 2019 for a set of forest bird species). As a consequence, the degree to which climate impacts on species' occurrence or abundance directly (by affecting, e.g. thermoregulation, nest site selection, breeding phenology; Martin 2001; Leech and Crick 2007; Bernagaud et al. 2011; Bison et al. 2020) or indirectly, through e.g. its influence on vegetation structure and composition, is largely unknown. This is a highly relevant issue for ecology and conservation, especially because it is key to predict climate change effects on bird populations: species distribution changes and elevational shifts indeed are often interpreted as a thermal niche tracking but, if climate effects are mostly or exclusively indirect, such distribution 
changes will be rather a consequence of habitat tracking. In this case, predictive distribution modelling should account for future changes in vegetation structure and composition due to climate change and other (possibly interacting) factors such as human land use. Knowledge about the relative magnitude of direct and indirect climate effects would also allow to propose more effective conservation strategies and management measures, or to improve the existing ones.

In this study, we aimed to assess and disentangle the direct and indirect effects of local temperature on bird abundance. We focused on breeding birds in the European Alps, along a wide elevational gradient (1300-2700 m asl) including montane and subalpine forests, the treeline habitat and alpine grasslands and rocky areas at the highest elevation. To our best knowledge, there are no previous studies aimed at quantitatively disentangling direct and indirect effects of local climate on species distribution/abundance encompassing such a wide elevational gradient. We expected a clear indirect effect of local temperature in all bird species: across such a wide elevational gradient, with forest gradually transitioning into alpine grassland, a strong effect of local climate on vegetation should be supposed, as climate is the main determinant of vegetation characteristics, and a definitive effect of vegetation on birds can be expected due to the striking differences in vegetation structure and composition along the gradient. Concerning the direct effect of local temperature, we expected strong interspecific differences, rather than generalized patterns, as a consequence of species-specific thermal niches and different degree of overlap with the climatic conditions of the study area. More specifically, we expected mountain generalist species to be more associated with warmer sites, given the harsh climate of our innerAlpine study area (Adler et al. 2015). Conversely, for mountain specialists (e.g. water pipit Anthus spinoletta), we expected a preference for relatively cold microclimates (Chamberlain et 
89 al. 2013; Brambilla et al. 2016, 2017; mountain specialist vs generalists were distinguished

90 following Lehikoinen et al. 2018).

91

92 Materials and methods

93

94

Data collection

95

Data were collected as previously described in Ceresa et al. (2020a). Specifically, fieldwork took place in the central-eastern Italian Alps (Wipptal, South Tyrol), immediately south of the main Alpine watershed, within a 3400 ha-wide area $\left(46.96^{\circ} \mathrm{N}, 11.50^{\circ} \mathrm{E}\right)$. This area spans from approximately $1300 \mathrm{~m}$ asl (just above the bottom valley) to more than $2700 \mathrm{~m}$ asl at the highest peaks. At lower elevation, mountainsides are mostly covered by woodlands, dominated by spruce Picea abies and European larch Larix decidua. Above the timberline (approximately 2000

m asl, but highly variable), wide areas are covered by bushes (mainly Rhododendron spp.) and scattered larches, whereas alpine grasslands, rocks and scree slopes characterize the upper elevation belt.

Birds were surveyed during the breeding season of most local breeding species (May -

July) in 2018, by means of point counts ( $\mathrm{N}=109$, Fig. 1) carried out by expert ornithologists.

The rugged topography, and the consequent low accessibility of some areas, made a random selection of the sampling points unfeasible. For this reason, we carried out the point counts along accessible transects, often along footpaths; we chose the location of each point based on a minimum distance of $200 \mathrm{~m}$ to the previous one, in order to avoid potential replicated counts of

111 the same individuals (Chamberlain et al. 2016). 
At each sampling point, the surveyor recorded all birds observed or heard during $10 \mathrm{~min}$

113 within a 100 m radius. All points were visited three times (survey sessions: 30 May - 6 June, 19

$114-23$ June and $13-18$ July). The survey timing allowed excluding the main migration periods of

115 locally breeding species. Counts were carried out in the morning, between 5:30 and 11:30, and

116 avoiding poor weather conditions (i.e., rain or strong wind).

117 Vegetation and other land cover characteristics within a $100 \mathrm{~m}$ radius were recorded at

118 each sampling point by the surveyor, with the aid of detailed aerial photos (as described in

119 Ceresa et al. 2020a). These variables included the percentage cover of tree canopy (i.e.,

120 vegetation higher than $2 \mathrm{~m}$ ), bushes (woody vegetation lower than $2 \mathrm{~m}$, mostly represented by

121 Rhododendron shrublands), grassland (areas with no canopy and covered by grassland

122 vegetation) and rocks/scree (emerging bedrock or scree-covered patches). The percentage cover

123 of each variable was thus visually estimated in the field to the nearest $5 \%$. Variables covering

124 less than $5 \%$ of the plot surface (as defined by the 100 m radius) were assigned a $1 \%$ cover

125 value. We also recorded information about woodland composition, by visually estimating the

126 proportion of tree canopy cover occupied by each arboreal species (excluding rare species, i.e.

127 representing less than $20 \%$ of the tree canopy cover).

128 In order to obtain climatic information at the site level, at each sampling point we placed

129 an iButton data logger (models DS1921G and DS1922L, Maxim Integrated, San Jose, CA),

130 which recorded temperatures hourly during the entire study period. Loggers were placed at the

131 ground level and were protected from the direct solar radiation by means of a white plastic panel.

132 Further details about loggers' placement and use, as well as the temperature trends recorded at

133 each point during the study period, are provided in Ceresa et al. (2020a). As we collected such

134 fine-scale temperature values, we did not consider topographic variables in our study. In fact, the 
135 effects of topography on bird abundance are very likely to be largely indirect, through a strong

136 influence on microclimate (especially temperature) and, consequently, also on vegetation. Our

137 fine-scale temperatures were indeed clearly related to both elevation and aspect, as expected (see

138 Fig S1). Relevant direct effects of topography on bird abundance (non-mediated by local

139 temperature and vegetation) are indeed hardly to occur, especially for elevation and aspect.

141 Statistical analysis

143 We used structural equation modelling to disentangle the direct effect of microclimate on bird abundance and the indirect effects of local temperature, mediated by vegetation characteristics.

145 Structural equation modelling consists in a multivariate linear regression analysis, which allows 146 assessing the effect of a predictor on a dependent variable through mediating variables.

147 Therefore, following this approach, it is possible to model simultaneously both direct and 148 indirect effect of a predictor on a dependent variable (Rosseel 2012). In the model structure we 149 adopted, variables describing vegetation characteristics represented the mediating variables in 150 the indirect pathways relating local temperature and bird abundance (see the path diagrams in 151 Fig. 2). Models were fitted using the sem function of package lavaan version 0.6-7 (Rosseel 152 2012) in program R version 3.5.3 (R Core Team 2019); we used the Satorra-Bentler maximum 153 likelihood test statistics, which provides model fit measures that are robust to data non-normality 154 (Satorra and Bentler 1994). We considered standardized path coefficient as significant at $\mathrm{p} \leq 0.1$, 155 to reduce the risk of type II error associated with the adopted statistical approach (Shipley 2016). 156 An indirect effect was considered as significant when all single path coefficients of the indirect 
157 pathway were significant at $\mathrm{p} \leq 0.1$. We compared direct and indirect effects of local temperature 158 by comparing the standardized coefficients of direct and indirect pathways.

To describe vegetation characteristics in our models, we used two principal components describing overall $60 \%$ of the variability in the vegetation data collected in the field (PC1 $=40 \%$, PC2 $=20 \%$ ). Principal component analysis was carried out using the prcomp function in the base $\mathrm{R}$ package. The first component was positively associated with forested areas and negatively with open areas (grassland and rocks), while the second component described a gradient in woodland composition (it was negatively associated with larch, one of the two dominant arboreal species), as well as the degree of grassland cover in open areas (positive association with rocks, negative with grassland; see Tab.1). As local climatic predictor, we used the mean temperature calculated for each sampling point across the entire study period, because it allows describing the general climatic conditions at a location (Virkkala et al. 2008; Stralberg et al. 2009). Mean temperatures during the study period varied across the study area between 6.6 and $14.8^{\circ} \mathrm{C}$, and obviously showed a clear trend along the elevation gradient (Fig. S1). As a measure of bird abundance, for each species we used the maximum number of individuals detected at each sampling point during the three sampling sessions. Unlike other studies dealing with mountain species' ecology, but not aimed at quantitative disentangling direct and indirect climate effects (e.g. Chamberlain et al. 2013; Ceresa et al. 2020a), we considered the points recorded over the complete elevational gradient for all species. This implied that, for each species, we included also areas with clearly unsuitable vegetation characteristics. Given that vegetation characteristics are largely determined by local climate, the selection of sub-samples of the sampling points based on vegetation characteristics (as frequently done in other studies with different aims), would have biased the estimation of the indirect temperature effects on bird abundance (likely 
180 leading to strong underestimation of such effects). We only considered those species detected at

181 least once at a minimum of 20 sampling points, i.e., 15 species. These species (listed in Tab. 2)

182 show a variety of different habitat preferences and specialization, as well as different nesting

183 habits and migration strategies, therefore our results are based on a highly representative species 184 set.

185 We evaluated model goodness-of-fit by a chi-square fit statistic, which indicates a 186 significant lack of fit when $\mathrm{p}<0.05$ (Hooper et al. 2008). We also used other fit metrics 187 commonly adopted in structural equation modelling: Comparative Fit Index (CFI), Tucker-Lewis 188 Index (TLI), root mean square error of approximation (RMSEA) and standardized root mean square residual (SRMR). A good model fit is indicated by CFI and TLI $>0.95$, RMSEA $<0.07$ and SRMR $<0.05$ (Hooper et al. 2008). Using and reporting such a variety of fit metrics is recommended in structural equation modelling, because each one reflects a different aspect of model fit (Crowley and Fan 1997; Hooper et al. 2008). In order to test for spatial autocorrelation, we calculated Moran's I for model residuals using ArcGis 10.8 (ESRI, Redlands, CA). Moran's I values $>0.3$ are considered as relatively large (Lichstein et al. 2002).

\section{Results}

For all species, structural equation models indicated a significant effect of vegetation characteristics on bird abundance (Tab. 2). Out of 15 species, PC1 had a significant effect in 14 and PC2 in 10 species. Given the significant effect of temperature on both PC1 $(\beta=0.54, p<$ $0.001)$ and PC2 $(\beta=-0.16, p=0.063)$, indirect pathways were always significant in case of significant effect of a principal component on bird abundance. Indirect temperature effects were 
203 indeed found in all species, while direct temperature effects occurred in 7 species (Tab. 2). When

204 present, direct temperature effects were always positive and showed a highly variable relative

205 importance compared to indirect effects (Tab. 2). Variance in bird abundance explained by

206 structural equation models ranged between $11 \%$ and $68 \%$, with only 4 species below $20 \%$ (Tab.

207 2). For all species, models fitted the data well according to the chi-square test $\left(\chi^{2}=1.265\right.$, $\mathrm{df}=1$,

$208 \mathrm{p}=0.261)$ and all the other fit metrics (CFI and TLI $>0.95$, RMSEA $<0.07$ and $\mathrm{SRMR}<0.05)$.

209 For 7 species, Moran's I test indicated the lack of spatial autocorrelation (Moran's I range: -

$210 \quad 0.037-0.065 ; \mathrm{p}>0.05 ;$ see Tab. S1 in the Supplementary Materials). In the other species the test

211 was significant, but with very low or low Moran's I values (approx. 0.1-0.2; Tab. S1), indicating

212 a weak clustering that is very unlikely to affect results. The only exception is represented by the

213 common chiffchaff Phylloscopus collybita, which showed a relatively high spatial

214 autocorrelation (Moran's I = 0.414); the results for this species should be cautiously considered.

Discussion

217

Disentangling direct and indirect effects of climate on species occurrence and abundance is crucial to assess distribution and population drivers, and to evaluate the potential impacts of climate change on wild species (de Chazal and Rounsevell 2009). The correlative link between climate and species (especially for homoeotherm animals) often reflects an indirect effect, which

222 is actually mediated by other factors associated with climate, such as habitat characteristics or 223 the availability of key resources (Brambilla et al. 2019). Here, we investigated the drivers of bird 224 abundance in a mountain context, where climate and habitat effects are intermingled, explicitly distinguishing between direct and vegetation-mediated impacts of local temperatures. 
227 characteristics on the abundance of all the species we considered. This suggests that such a

228 pattern could be generalized, or at least very common in bird communities of temperate

229 mountain regions, given the wide ecological spectrum represented in our species set.

230 Temperatures at sampling sites had a significant effect on both principal components describing

231 vegetation, with a stronger influence on the most important one (PC1), which accounts for the

232 difference between forested and open areas (Fig. 2). This is not surprising, as climatic factors are

233 crucial in determining the treeline position, jointly with several additional factors such as human

234 land use and geomorphology (Körner and Paulsen 2004; Chauchard et al. 2010; Leonelli et al.

235 2010). The observed effects of the two vegetation principal components on bird abundance are

236 fully consistent with the known habitat preferences of each species (e.g., Brichetti and Fracasso

237 2007, 2008; Chamberlain et al. 2016). Unlike indirect effects, direct temperature effects only

238 occurred in some species, consistently with our expectation of strong interspecific differences

239 and lack of generalized patterns.

Direct effects of local climate for birds in the Alps

All the seven species showing significant direct temperature effects (see Tab. 2) are woodland or shrubland birds and are not mountain specialists. The distribution of some of these species in Italy widely overlaps with the main mountain chains, but they cannot be considered as mountain specialists because they breed also in hilly and low elevation areas, and in nearby countries they

247 are also widely distributed across lowlands (coal tit Periparus ater, crested tit Lophophanes

248 cristatus, Eurasian bullfinch Pyrrhula pyrrhula, goldcrest Regulus regulus, mistle thrush Turdus 
249 viscivorus; species distributions are available in BirdLife International 2021). Given the positive

250 direct temperature effect on their abundance, at least part of the woodland within our study area

251 is likely colder than the thermal optimum of these species; our inner-Alpine study area is indeed

252 characterized by an especially severe climate, with long-lasting snow cover (Adler et al. 2015).

253 Such temperature effect could be emphasized by the early breeding of these species: warmer

254 sites likely provide better conditions early in the reproduction season, especially for what

255 concerns the availability of key poikilothermic prey (invertebrates). Two other species showing a

256 positive direct temperature effect (Eurasian blackcap Sylvia atricapilla and European robin

257 Erithacus rubecula) are generalist species with very broad habitat niche, and are very common at

258 low and middle elevations; our study area is probably located towards the coldest extreme of

259 their thermal niche.

260

In the two open habitat species for which we obtain a sufficient sample for the analysis

261 (water pipit and northern wheatear Oenanthe oenanthe), we found a significant negative

262 temperature effect on abundance, but exclusively indirectly via vegetation. This suggests that, at

263 least in inner Alpine areas like our study site, maintaining and correctly managing high-elevation

264 pastures and grasslands would probably represent effective conservation measures for these

265 species, as proposed also in other studies (e.g. Chamberlain et al. 2013, Brambilla et al. 2018,

266 2020). Differently from what we expected, our results indeed did not show a direct temperature

267 effect for the water pipit, a mountain-specialist grassland bird that had been reported to be

268 associated with cold climates in other studies focusing on species occurrence (e.g. Brambilla et

269 al. 2017, 2019), and to experience variation in breeding success according to nest-site orientation

270 (Rauter et al. 2002). The most likely explanation for such differences is that, in this cold, inner-

271 Alpine area, the climatic conditions of alpine grasslands are close to the thermal optimum of this 
272 species. On the other side, the previous studies reporting an effect of local climate on this

273 species' occurrence were carried out at a much larger scale, including also low-elevation,

274 warmer massifs (Brambilla et al. 2017), or took place in more southern and definitely warmer

275 mountain chains (i.e., Apennines; Brambilla et al. 2019, 2020). The large differences in

276 temperature ranges between our and those previously investigated study areas probably explains

277 the differences with our results, which revealed no direct effect of temperature on abundance

278 (besides the different focus on occurrence vs. local abundance, and the different statistical

279 approach). This highlights the importance of spatial scale when studying the influence of

280 climatic factors on species distribution and abundance, as different or even contrasting results

281 may arise from analyses carried out at different scales (e.g. Franklin et al. 2013, Brambilla et al.

282 2019).

283

While the proportion of variance in bird abundance explained by our models was good

284 for most species (see Tab. 2), the proportion of unexplained variance suggests the more or less important effect of additional factors not considered in this study, such as spatial variation in predation intensity and other biotic interactions, microhabitat characteristics, and possibly also terrain slope in some species (see, e.g, Thompson 2007; Sherry et al. 2015; Freeman and Montgomery 2016; Brambilla et al. 2019). We could not consider also the possible effect of precipitations on bird abundance, because we did not collect precipitation data in the field. However, over such a restricted study area the spatial variation of precipitation is likely to be affected almost only by the reduction of temperatures with elevation (through orographic effect), which should be strictly related to our fine-scale temperature data. Therefore, precipitation data would likely add only limited information to our models. 
295

296

297

298

299

300

301

302

303

304

305

306

307

308

309

310

311

312

313

314

315

316

Implications for research and conservation

Our results are largely consistent with those reported by Duclos et al. (2019), who investigated a set of forest bird species breeding in a North American mountain area and found an indirect effect of climate via vegetation in all species, while directs effects occurred only in part of the species and strongly varied in their magnitude. This suggests that such climate-species relationship patterns may be widespread in mountain bird communities, at least in temperate regions and in areas where the number of high-elevation specialists is often very low, as in our study system. This should be taken into account when investigating and predicting future bird distribution and abundance. This could be particularly relevant for generalist mountain birds, as in many cases they may be largely tracking suitable habitat, rather than thermal niches, as our results suggest for several species inhabiting different habitats and different elevation belts.

Consequently, accounting also for future changes in vegetation structure and composition would likely allow more reliable predictions than using climatic factors only; this is a complex task, as both human land use and climatic factors should be considered to forecast vegetation changes. In addition, vegetation changes may lag largely behind climate change (Iverson et al. 2008;

Stralberg et al. 2015): in e.g. the northeastern United States tree species shift has been forecasted to occur in some centuries (Wang et al. 2016). Such a complex and context-dependent scenario (species-specific direct and indirect climate effects, influence of human land use) may help to explain why elevational range shifts of mountain bird distribution assessed until now are poorly consistent across different studies in both magnitude and direction (i.e., uphill/downhill; see Scridel et al. 2018), in spite of the global scale temperature increase. 

influenced by human activities, direct effects are likely to impact bird population rapidly, by affecting, e.g., breeding phenology, prey availability, survival and breeding success (e.g.

Rodríguez and Bustamante 2003; Dunn 2004; Wesołowski et al. 2016; Bison et al. 2020; Ceresa et al. 2020b; Strinella et al. 2020). According to our results, at least in the innermost part of the European Alps the ongoing temperature increase may favour some generalist woodland and shrubland bird species (as suggested, e.g., by Solonen et al. 2007; Scridel et al. 2017). This could occur due to wider woodland areas with adequate local climatic conditions for these species, but also because of a possibly longer breeding season (Bison et al. 2020). According to Ceresa et al. (2020a), in our study area European robins select warmer areas for breeding during the first part of the reproductive season, thus higher spring temperatures would likely allow start breeding earlier across wider areas, with a consequently larger time window available for subsequent reproduction attempts.

The indirect effect of local climate we found in the two open habitat species here considered highlights the importance of conservation and management of Alpine grasslands for those species. Uphill treeline shift and shrubland expansion have been recorded in several mountain ranges, including the European Alps, and besides temperature increase they are often strongly promoted by land abandonment (Gehrig-Fasel et al. 2007; Myers-Smith et al. 2011). Therefore, habitat loss for these species needs to be counteracted by maintaining cattle grazing in mountain pastures, managed in an extensive way to avoid overgrazing, which leads to grassland and soil degradation (Garcia-Pausas et al. 2017) and can be detrimental to open-habitat bird species (Brambilla et al. 2020). In addition, the construction of new touristic infrastructures such 
340 communities (Rolando et al. 2007; Caprio et al. 2011) and are predicted to increasingly overlap

341 with the distribution of high-elevation specialist birds as a consequence of climate change

342 (Brambilla et al. 2016). Other bird species connected to high-elevation open areas could be

343 affected by climatic factors also directly, e.g. the white-winged snowfinch Montifringilla nivalis

344 (Brambilla et al. 2019), and unfortunately we did not obtain a sufficient sample for this species

345 and other locally breeding high-elevation specialists (alpine accentor Prunella collaris, alpine

346 chough Pyrrhocorax graculus). However, also in case of direct climate effects the

347 aforementioned conservation measures would be recommendable, in order to try buffering

348 against climate change. Given the high terrain complexity of mountain ranges, across large areas

349 of suitable habitat some sites may maintain adequate microclimatic conditions for cold-

350 associated species, possibly acting as local 'refugia' despite temperature warming at larger scale

351 (Morelli et al. 2016). Therefore, avoiding habitat loss and degradation as previously described

352 could increase the future amount of refugia maintaining both vegetation and microclimatic

353 suitable characteristics. Furthermore, correctly managed cattle grazing could provide/maintain

354 micro-habitats suitable for foraging for species potentially vulnerable to earlier snowmelt

355 (Brambilla et al. 2018).

356

\section{Conclusions}

358

359 The impact of climate and land-use/land-cover changes are among the major threats to

360 biodiversity worldwide, and will exacerbate in the future decades. Properly addressing the nature

361 of their effects on wild species is key to understanding impacts and developing conservation

362 strategies. In this study, considering a set of bird species along a broad elevational gradient, we 
363 found a generalised indirect effect via vegetation of local temperatures on birds abundance, while

364 direct effects were less common and were found in some mountain generalist birds. Our work

365 provides an example of disentangling causes and effects when dealing with the combined impact

366 of habitat and local climate on target organisms; a similar framework may be used to address

367 effects and impacts on many other ecosystems, promoting a deeper understanding of species'

368 response to habitat and climate and the relative changes.

369

370

\section{Acknowledgements}

371 The present study has been financed by the Research fund of the Museums of South Tyrol,

372 within the project 'The distribution and conservation status of birds in South Tyrol', CUP

373 H53C17000260005. We thank Prof. Emilio Barba (Institute Cavanilles of Biodiversity and

374 Evolutionary Biology - University of Valencia) for providing part of the temperature loggers. We 375 are very grateful to D. Chamberlain and an anonymous reviewer for helpful comments on a first 376 draft of the manuscript.

\section{References}

J, Zingerle C, Marigo G, Fischer A, Seiser B (2015) Il clima del Tirolo - Alto Adige - Bellunese.

382 Zentralanstalt fur Meteorologie und Geodynamik, Ripartizione Protezione antincendi e civile -

383 Provincia Autonoma di Bolzano, Agenzia Regionale per la Prevenzione e Protezione Ambientale 384 del Veneto. 
386 Barnagaud JY, Crochet PA, Magnani Y, Bernard Laurent A, Menoni E, Novoa C, Gimenez O

387 (2011) Short-term response to the North Atlantic Oscillation but no long-term effects of climate

388 change on the reproductive success of an alpine bird. J Ornithol 152:631-641.

389 https://doi.org/10.1007/s10336-010-0623-8

390

391 BirdLife International (2021) IUCN Red List for birds. Downloaded from

392 http://www.birdlife.org on 15/02/2021.

393

394

Bison M, Yoccoz NG, Carlson B, Klein G, Laigle I, Van Reeth C, Asse D, Delestrade A (2020)

395

Best environmental predictors of breeding phenology differ with elevation in a common

woodland bird species. Ecol Evol 10:10219-10229. https://doi.org/10.1002/ece3.6684

397

398

399

Boyle WA, Martin K (2015) The conservation value of high elevation habitats to North American migrant birds. Biol Conserv 192:461-476.

400

https://doi.org/10.1016/j.biocon.2015.10.008

401

402

Brambilla M, Caprio E, Assandri G, Scridel D, Bassi E, Bionda R, Celada C, Falco R, Bogliani

403

G, Pedrini P, Rolando A, Chamberlain D (2017) A spatially explicit definition of conservation

404

priorities according to population resistance and resilience, species importance and level of threat

405 in a changing climate. Divers Distrib 23:727-738. https://doi.org/10.1111/ddi.12572

406 
407 Brambilla M, Gustin M, Cento M, Ilahiane L, Celada C (2019) Predicted effects of climate

408 factors on mountain species are not uniform over different spatial scales. J Avian Biol 50.9.

409 https://doi.org/10.1111/jav.02162

410

411

Brambilla M, Gustin M, Cento M, Ilahiane L, Celada C (2020) Habitat, climate, topography and

412 management differently affect occurrence in declining avian species: Implications for

413 conservation in changing environments. Sci Total Environ 742:140663.

414 https://doi.org/10.1016/j.scitotenv.2020.140663

415

416

Brambilla M, Pedrini P, Rolando A, Chamberlain DE (2016) Climate change will increase the potential conflict between skiing and high-elevation bird species in the Alps. J

Biogeogr 43:2299-2309. https://doi.org/10.1111/jbi.12796

419

420

Brambilla M, Resano-Mayor J, Scridel D, Anderle M, Bogliani G, Braunisch V, Capelli F,

Cortesi M, Horrenberger N, Pedrini P, Sangalli B, Chamberlain D, Arlettaz R, Rubolini D (2018)

422

Past and future impact of climate change on foraging habitat suitability in a high-alpine bird

423 species: Management options to buffer against global warming effects. Biol Conserv 221:209218. https://doi.org/10.1016/j.biocon.2018.03.008

425

426

Brambilla M, Scridel D, Sangalli B, Capelli F, Pedrini P, Bogliani G, Rubolini D (2019)

427 Ecological factors affecting foraging behaviour during nestling rearing in a high-elevation

428 species, the White-winged Snowfinch (Montifringilla nivalis). Ornis Fenn 96:142-151. 
430 Brichetti P, Fracasso G (2007) Ornitologia italiana, Vol. 4 -Apodidae-Prunellidae. Oasi Alberto 431 Perdisa Editore.

432

433 Brichetti P, Fracasso G (2008) Ornitologia italiana, Vol. 5 - Turdidae-Cisticolidae. Oasi Alberto 434 Perdisa Editore.

435

436 Cadena CD, Kozak KH, Gomez JP, Parra JL, McCain CM, Bowie RCK, Carnaval AC, Moritz C, 437 Rahbek C, Roberts TE, Sanders NJ, Schneider CJ, VanDerWal J, Zamudio KR, Graham CH 438 (2012) Latitude, elevational climatic zonation and speciation in new world vertebrates. Proc R 439 Soc B 279: 194-201. https://doi.org/10.1098/rspb.2011.0720

440

441 Caprio E, Chamberlain DE, Isaia M, Rolando A (2011) Landscape changes caused by high 442 altitude ski-pistes affect bird species richness and distribution in the Alps. Biol 443 Conserv 144:2958-2967. https://doi.org/10.1016/j.biocon.2011.08.021

445 Ceresa F, Brambilla M, Rizzolli F, Monrós JS, Kranebitter P (2020a). Within-season movements 446 of Alpine songbird distributions are driven by fine-scale environmental characteristics. Sci Rep 447 10: 5747. https://doi.org/10.1038/s41598-020-62661-0

448

449 Ceresa F, Belda EJ, Brambilla M, Gómez J, Mompó C, Monrós JS (2020b). Factors shaping 450 breeding phenology in birds: an assessment of two sympatric Acrocephalus warblers with 451 different life histories. Ardeola 67:371-385. https://doi.org/10.13157/arla.67.2.2020.ra9 
453 Chamberlain DE, Brambilla M, Caprio E, Pedrini P, Rolando A (2016) Alpine bird distributions

454 along elevation gradients: the consistency of climate and habitat effects across geographic

455 regions. Oecologia 181:1139-1150. https://doi.org/10.1007/s00442-016-3637-y

456

457 Chamberlain DE, Negro M, Caprio E, Rolando A (2013) Assessing the sensitivity of alpine birds

458 to potential future changes in habitat and climate to inform management strategies. Biol

459 Conserv 167:127-135. https://doi.org/10.1016/j.biocon.2013.07.036

460

461 Chauchard S, Beilhe F, Denis N, Carcaillet C (2010) An increase in the upper tree-limit of silver

462 fir (Abies alba Mill.) in the Alps since the mid-20th century: A land-use change phenomenon.

463 Forest Ecol Manag 259:1406-1415. https://doi.org/10.1016/j.foreco.2010.01.009

464

465 de Chazal J, Rounsevell MDA (2009) Land-use and climate change within assessments of

466 biodiversity change: a review. Glob Environ Change 19:306-315.

467 https://doi.org/10.1016/j.gloenvcha.2008.09.007.

468

469 Cheviron ZA, Brumfield RT (2012) Genomic insights into adaptation to high-altitude

470 environments. Heredity 108:354-361. https://doi.org/10.1038/hdy.2011.85

471

472 Crowley SL, Fan X (1997) Structural Equation Modeling: Basic Concepts and Applications in 473 Personality Assessment Research. J Pers Assess 68:508-31.

474 
475 De Gabriel Hernando M, Fernández-Gil J, Roa I, Juan J, Ortega F, de la Calzada F, Revilla E 476 (2021) Warming threatens habitat suitability and breeding occupancy of rear-edge alpine bird 477 specialists. Ecography 44:1191-1204. doi: 10.1111/ecog.05593

478

479 Dirnböck T, Essl F, Rabitsch W (2011) Disproportional risk for habitat loss of high altitude 480 endemic species under climate change. Glob Change Biol 17:990-996.

481 https://doi.org/10.1111/j.1365-2486.2010.02266.x

482

483

Duclos TR, DeLuca WV, King DI (2019) Direct and indirect effects of microclimate on bird 484 abundance along elevation gradients in the Northern Appalachian mountains. Divers Distrib 25: 485 1670-1683. https://doi.org/10.1111/ddi.12968

486

487

Dunn P (2004) Breeding dates and reproductive performance. Adv Ecol Res 35:69-87.

488 https://doi.org/10.1016/S0065-2504(04)35004-X

489

490

Elsen PR, Tingley MW, Kalyanaraman R, Ramesh K, Wilcove DS (2017) The role of

491 competition, ecotones, and temperature in the elevational distribution of Himalayan birds.

492

Ecology 98:337-348. https://doi.org/10.1002/ecy.1669

493

494

Engler JO, Stiels D, Schidelko K, Strubbe D, Quillfeldt P, Brambilla M (2017) Avian SDMs:

495 current state, challenges, and opportunities. J Avian Biol 48:1483-1504.

496 https://doi.org/10.1111/jav.01248

497 
498 Franklin J, Davis FW, Ikegami M, Syphard AD, Flint LE, Flint AL, Hannah L (2013) Modeling

499 plant species distributions under future climates: how fine scale do climate projections need to

500 be? Glob Change Biol 19:473-483. https://doi.org/10.1111/gcb.12051

501

502 Freeman BG, Montgomery G (2016) Interspecific aggression by the Swainson's thrush

503 (Catharus ustulatus) may limit the distribution of the threatened Bicknell's thrush (Catharus

504 bicknelli) in the Adirondack Mountains. Condor 118: 169-178.

505 https://doi.org/10.1650/CONDOR-15-145.1

506

507 Frey SJ, Hadley AS, Betts MG (2016) Microclimate predicts within-season distribution 508 dynamics of montane forest birds. Divers Distrib 22:944-959. https://doi.org/10.1111/ddi.12456

509

510 Garcia-Pausas J, Romanyà J, Montané F, Rios AI, Taull M, Rovira P, Casals P (2017) Are soil

511 carbon stocks in mountain grasslands compromised by land-use changes?. In High mountain 512 conservation in a changing world (pp. 207-230). Springer.

513

514 Gehrig-Fasel J, Guisan A, Zimmermann NE (2007) Tree line shifts in the Swiss Alps: climate

515 change or land abandonment? J Veg Sci 18:571-582. https://doi.org/10.1111/j.1654-

516 1103.2007.tb02571.x

517

518 Goodenough AE and Hart AG (2013) Correlates of vulnerability to climate-induced distribution

519 changes in European avifauna: habitat, migration and endemism. Clim Change 118:659-669.

520 https://doi.org/10.1007/s10584-012-0688-x 
522 Hooper D, Coughlan J, Mullen M (2008) Structural equation modelling: Guidelines for

523 determining model fit. Electron J Bus Res Methods 6:53-60.

524

525 Iverson L, Prasad A, Matthews S (2008) Modeling potential climate change impacts on the trees 526 of the Northeastern United States. Mitig Adapt Strateg Glob Chang 13:487-516.

527 https://doi.org/10.1007/s11027-007-9129-y

528

529 Jähnig S, Sander MM, Caprio E, Rosselli D, Rolando A, Chamberlain D (2020) Microclimate

530 affects the distribution of grassland birds, but not forest birds, in an Alpine environment. J

531 Ornithol 161:677-689. https://doi.org/10.1007/s10336-020-01778-5

532

533 Jongsomjit D, Stralberg D, Gardali T, Salas L, Wiens J (2013) Between a rock and a hard place:

534 the impacts of climate change and housing development on breeding birds in California. Landsc

535 Ecol 28:187-200. https://doi.org/10.1007/s10980-012-9825-1

536

537 Körner C, Ohsawa M (2006) Mountain systems. In Hassan, R., Scholes, R. and Ash, N. (eds)

538 Ecosystem and Human Well-being: Current State and Trends. Millennium Ecosystem

539 Assessment. Vol. 1: 681-716. Island Press.

540

541 Körner C, Paulsen J (2004) A world-wide study of high altitude treeline temperatures. J

542 Biogeogr 31:713-732. https://doi.org/10.1111/j.1365-2699.2003.01043.x 
544 Leech D, Crick HQP (2007) Influence of climate change on the abundance, distribution and

545 phenology of woodland bird species in temperate regions. Ibis 149:128-145.

546 https://doi.org/10.1111/j.1474-919X.2007.00729.X

547

548 Lehikoinen A, Brotons L, Calladine J, Campedelli T, Escandell V, Flousek J, Grueneberg C,

549 Haas F, Harris S, Herrando S, Magne Husby M, Jiguet F, Kålås JA, Åke Lindström Å, Lorrillière

550 R, Molina B, Pladevall C, Calvi G, Sattler T, Schmid H, Sirkiä1 PM, Teufelbauer N, Trautmann

551 S (2019) Declining population trends of European mountain birds. Glob Change Biol 25: $577-$

552588.

553 https://doi.org/10.1111/gcb.14522

554

555 Leonelli G, Pelfini M, di Cella UM, Garavaglia V (2011) Climate warming and the recent

556 treeline shift in the European Alps: the role of geomorphological factors in high-altitude

557 sites. Ambio 40: 264-273. https://doi.org/10.1007/s13280-010-0096-2

558

559 Lichstein JW, Simons TR, Shriner SA, Franzreb KE (2002) Spatial autocorrelation and

560 autoregressive models in ecology. Ecol Monogr 72:445-463.

561

562 Mantyka-Pringle CS, Martin TG, Rhodes JR (2012) Interactions between climate and habitat loss

563 effects on biodiversity: a systematic review and meta-analysis. Glob Change Biol 18:1239-1252.

564 https://doi.org/10.1111/j.1365-2486.2011.02593.x

565 
566 Martin TE (2001) Abiotic vs. biotic influences on habitat selection of coexisting species: Climate

567 change impacts? Ecology 82:175-188. https://doi.org/10.1890/0012-

568 9658(2001)082[0175:AVBIOH]2.0.CO;2

569

570 Morelli TL, Daly C, Dobrowski SZ, Dulen DM, Ebersole JL, Jackson ST, Lundquist JD, Millar

571 C I, Maher SP, Monahan WP, Nydick KR, Redmond KT, Sawyer SC, Stock S, Beissinger SR

572 (2016) Managing climate change refugia for climate adaptation. PLoS ONE 11:e0159909.

573 https://doi.org/10.1371/journal.pone.0159909

574

575 Myers N, Mittermeier RA, Mittermeier CG, da Fonseca GAB, Kent J (2000) Biodiversity

576 hotspots for conservation priorities. Nature 403:853-858. https://doi.org/10.1038/35002501

577

578 Myers-Smith IH, Forbes BC, Wilmking M, Hallinger M, Lantz T, Blok D, Tape KD, Macias-

579 Fauria M, Sass-Klaassen U, Levesque E, Boudreau S, Ropars P, Hermanutz L, Trant A, Collier

580 LS, Weijers S, Rozema J, Rayback SS, Schmidt NM, Schaepman-Strub G, Wipf S, Rixen C,

581 Menard CC, Venn S, Goetz S, Andreu-Hayles L, Elmendorf S, Ravolainen V, Welker J, Grogan

582 P, Epstein HE, Hik DS (2011) Shrub expansion in tundra eco-systems: dynamics, impacts and

583 research priorities. Environ Res Lett 6:045509. https://doi.org/10.1088/1748-9326/6/4/045509

584

585 Pearce-Higgins JW, Eglington SM, Martay B, Chamberlain DE (2015) Drivers of climate change

586 impacts on bird communities. J Anim Ecol 84: 943-954. https://doi.org/10.1111/1365-

$587 \quad 2656.12364$

588

PeerJ reviewing PDF | (2021:07:64101:1:1:NEW 22 Oct 2021) 
589 Péron G, Altwegg R (2015) Twenty-five years of change in southern African passerine diversity:

590 nonclimatic factors of change. Glob Chang Biol 21:3347-3355.

591 https://doi.org/10.1111/gcb.12909

592

593 R Core Team (2019) R: A language and environment for statistical computing. Vienna, Austria:

594 R Foundation for Statistical Computing. Retrieved from https://www.r-proje ct.org/

595

596

Rauter CM, Reyer HU, Bollmann K (2002) Selection through predation, snowfall and

597 microclimate on nest-site preferences in the Water Pipit Anthus spinoletta. Ibis 144:433-444.

598 https://doi.org/10.1046/j.1474-919X.2002.00013.x

599

600 Rodriguez C, Bustamante J (2003) The effect of weather on lesser kestrel breeding success: can

601 climate change explain historical population declines? J Anim Ecol 72:793-810.

602 https://doi.org/10.1046/j.1365-2656.2003.00757.x

603

604 Rodríguez JP, Brotons L, Bustamante J, Seoane J (2007) The application of predictive modelling 605 of species distribution to biodiversity conservation. Divers Distrib 13:243-251.

606 https://doi.org/10.1111/j.1472-4642.2007.00356.x

607

608 Rolando A, Caprio E, Rinaldi E, Ellena I (2007) The impact of high-altitude ski-runs on alpine 609 grassland bird communities. J Appl Ecol 44:210-219. https://doi.org/10.1111/j.1365-

$610 \quad 2664.2006 .01253 . x$

611 
612 Rosseel Y (2012) Lavaan: An R package for structural equation modeling and more. Version 613 0.5-12 (BETA). J Stat Softw 48:1-36. http://hdl.handle.net/10.18637/jss.v048.i02

614

615 Ruggiero A, Hawkins BA (2008) Why do mountains support so many species of birds?

616 Ecography 31:306-315. https://doi.org/10.1111/j.0906-7590.2008.05333.x

617

618 Sala OE, Chapin FS, Armesto JJ, Berlow E, Bloomfield J, Dirzo R, Huber-Sanwald E,

619 Huenneke, LF, Jackson RB, Kinzig A, Leemans R, Lodge DM, Mooney HA, Oesterheld M, Poff

620 NL, Sykes MT, Walker BH, Walker M, Wall DH (2000) Global biodiversity scenarios for the

621 year 2100. Science (80)287:1770-1774. 10.1126/science.287.5459.1770

622

623 Satorra A, Bentler PM (1994) Corrections to test statistics and standard errors in covariance 624 structure analysis. In A. von Eye and C. C. Clogg (Eds.), Latent variables analysis: Applications 625 for developmental research (pp. 399-419). Sage Publications, Inc.

626

627 Scridel D, Bogliani G, Pedrini P, Iemma A, von Hardenberg A, Brambilla M (2017) Thermal

628 niche predicts recent changes in range size for bird species. Clim Res 73: 207-216.

629

630 Scridel D, Brambilla M, Martin K, Lehikoinen A, Iemma A, Matteo A, Jähnig S,

631 Caprio E, Bogliani G, Pedrini P, Rolando A, Arlettaz R, Chamberlain D (2018) A review

632 and meta-analysis of the effects of climate change on Holarctic mountain and upland bird

633 populations. Ibis 160:489-515. https://doi.org/10.1111/ibi.12585

634 
635 Sherry TW, Wilson S, Hunter S, Holmes RT (2015) Impacts of nest predators and weather on 636 reproductive success and population limitation in a long-distance migratory songbird. J Avian 637 Biol 46: 559-569. https ://doi.org/10.1111/jav.00536

638

639 Shipley B (2016) Cause and correlation in biology: A user's guide to path analysis, structural 640 equations and causal inference with R (2nd ed.). Cambridge University Press.

641

642 Solonen T (2005) Breeding of the tawny owl Strix aluco in Finland: responses of a southern 643 colonist to the highly variable environment of the north. Ornis Fenn 82: 97-106

644

645 Stralberg D, Jongsomjit D, Howell CA, Snyder MA, Alexander JD, Wiens JA, Root TL (2009)

646 Re-shuffling of species with climate disruption: a no-analog future for California birds? PLoS

647 One 4: e6825. https ://doi.org/10.1371/journ al.pone.0006825

648

649 Stralberg D, Bayne EM, Cumming SG, Sólymos P, Song SJ, Schmiegelow FKA (2015)

650 Conservation of future boreal forest bird communities considering lags in vegetation response to

651 climate change: A modified refugia approach. Divers Distrib 21:1112-1128. https

652 ://doi.org/10.1111/ddi.12356

653

654 Strinella E, Scridel D, Brambilla M, Schano C, Korner-Nievergelt F (2020) Potential sex-

655 dependent effects of weather on apparent survival of a high-elevation specialist. Sci Rep 10:1-13.

656 https://doi.org/10.1038/s41598-020-65017-w

657 
658 Thompson FR (2007) Factors affecting nest predation on forest songbirds in North America. Ibis 659 149: 98-109. https://doi.org/10.1111/j.1474-919X.2007.00697.x

660

661 Virkkala R, Heikkinen RK, Leikola N, Luoto M (2008) Projected large-scale range reductions of 662 northern-boreal land bird species due to climate change. Biol Conserv 141:1343-1353.

663 https://doi.org/10.1016/j.biocon.2008.03.007

664

665 Wang WJ, He HS, Thompson FR, Fraser JS, Dijak WD (2016) Changes in forest biomass and 666 tree species distribution under climate change in the Northeastern United States. Landsc Ecol 667 32:1399-1413. https://doi.org/10.1007/s10980-016-0429-z

668

669 Wesołowski T, Cholewa M, Hebda G, Maziarz M, Rowiński P (2016) Immense plasticity of 670 timing of breeding in a sedentary forest passerine, Poecile palustris. J Avian Biol 47:129-133.

671 https://doi.org/10.1111/jav.00733 
Figure 1

Study area

Distribution of the sampling points in the study area (central-eastern European Alps, Italy).

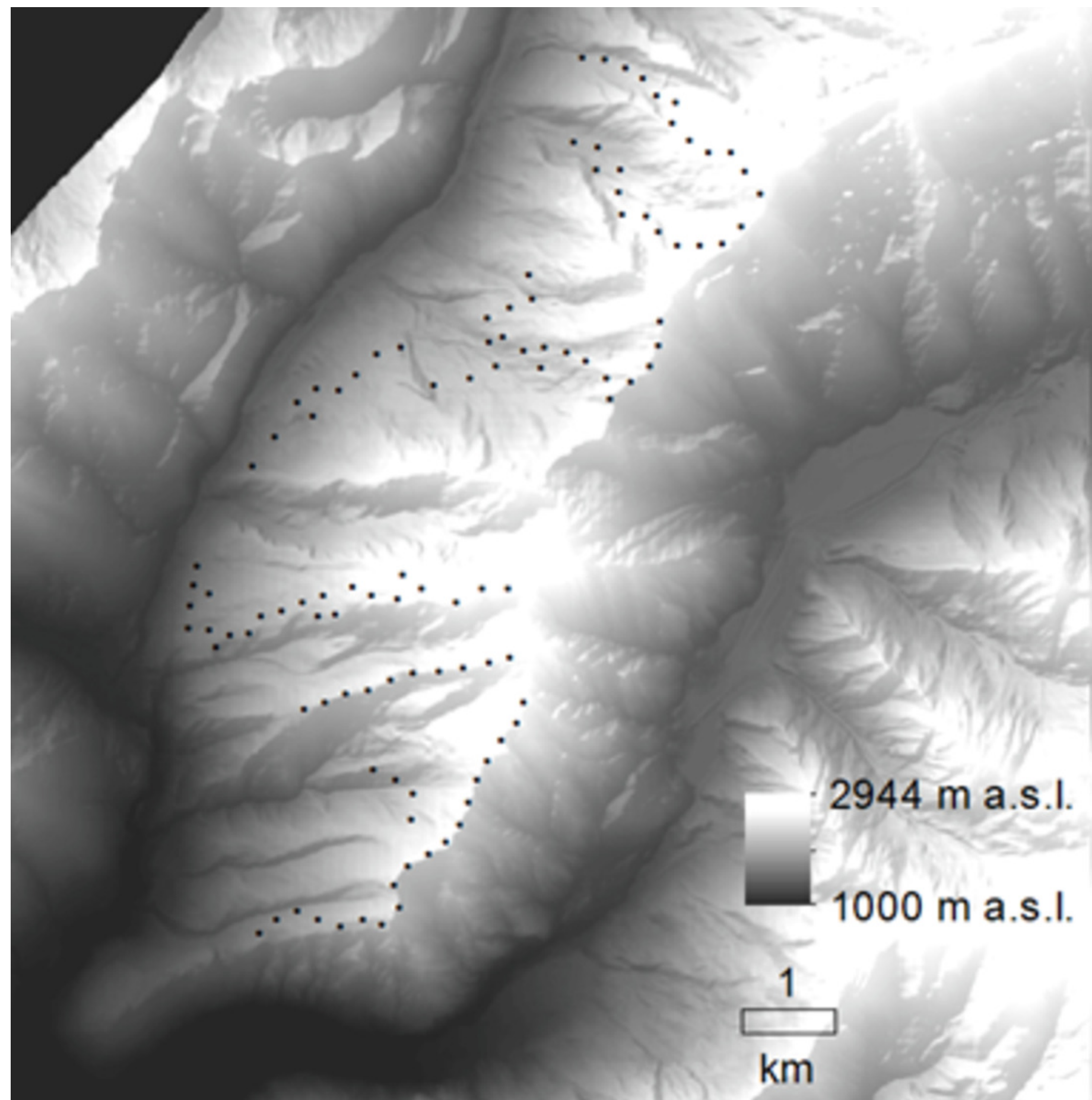


Figure 2

Relationship among temperature, vegetation characteristics and bird abundance.

Relationship among temperature, vegetation characteristics (PC1 and PC2) and bird abundance according to structural equation modelling in four of 15 investigated bird species breeding in a mountain area. The reported values are standardized regression coefficients and the asterisk indicate a significant effect $(p \leq 0.1)$.

Anthus spinoletta

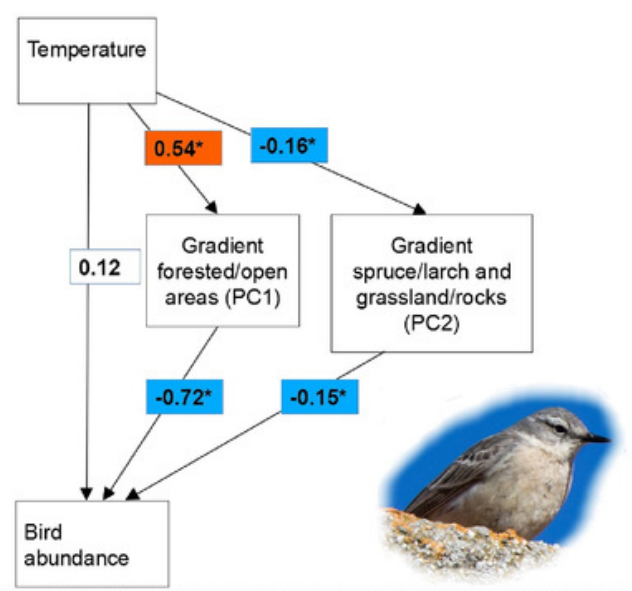

Erithacus rubecula

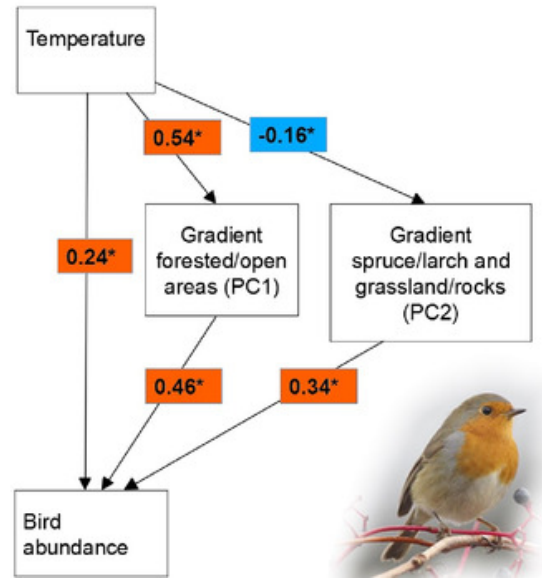

Prunella modularis
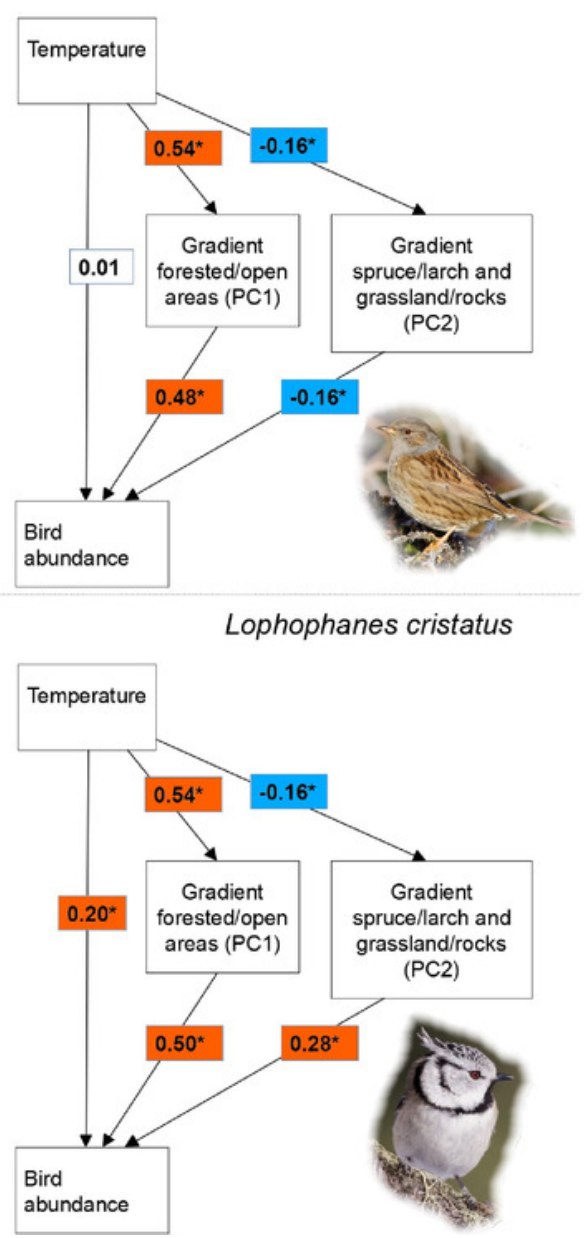


\section{Table $\mathbf{1}$ (on next page)}

Relationship between vegetation variables collected in the field and PCA components used to descibe vegetation

Relationship between the two principal components (used to describe vegetation structure and composition in structural equation models) and each land cover category. 
Table 1: Relationship between the two principal components (used to describe vegetation structure and composition in structural equation models) and each land cover category.

\begin{tabular}{lcc}
\hline Land cover category & PC1 & PC2 \\
\hline Bushes (\% cover) & 0.053 & -0.663 \\
Rocks/scree (\% cover) & -0.328 & 0.424 \\
Tree canopy (\% cover) & 0.572 & 0.340 \\
Undergrowth (\% cover) & 0.318 & -0.163 \\
Grassland (\% cover) & -0.493 & -0.368 \\
Larches (\% of total canopy cover) & 0.468 & -0.321 \\
\hline
\end{tabular}

1 


\section{Table 2 (on next page)}

Direct and indirect effects of local climate on bird abundance

Effects of vegetation (PC1 and PC2) and temperature on breeding bird abundance according to structural equation modelling ( $p$-values in parentheses), and variance in bird abundance explained $\left(R^{2}\right)$ for each species. Effects are reported as standardized coefficients. Only significant effects are reported ( $p \leq 0.1$ ). An indirect effect is considered significant when all path coefficients of the indirect effect path are significant at $p \leq 0.1$. Model structure is shown in Fig. 2. 
1 Table 2. Effects of vegetation (PC1 and PC2) and temperature on breeding bird abundance according to structural equation modelling 2 ( $\mathrm{p}$-values in parentheses), and variance in bird abundance explained $\left(\mathrm{R}^{2}\right)$ for each species. Effects are reported as standardized 3 coefficients. Only significant effects are reported $(p \leq 0.1)$. An indirect effect is considered significant when all path coefficients of the 4 indirect effect path are significant at $p \leq 0.1$. Model structure is shown in Fig. 2.

\begin{tabular}{|c|c|c|c|c|c|c|}
\hline Species & PC1 & PC2 & $\begin{array}{l}\text { Temperature } \\
\text { (direct effect) }\end{array}$ & $\begin{array}{c}\text { Indirect temperature effect } \\
\text { through } \mathrm{PC} 1\end{array}$ & $\begin{array}{c}\text { Indirect temperature effect } \\
\text { through PC2 }\end{array}$ & $\mathrm{R}^{2}$ \\
\hline Anthus spinoletta & $-0.716(0.000)$ & $-0.145(0.040)$ & & $-0.387(0.000)$ & $0.023(0.191)$ & 0.44 \\
\hline Certhia familiaris & $0.485(0.000)$ & $0.349(0.000)$ & & $0.262(0.000)$ & $-0.055(0.080)$ & 0.37 \\
\hline Erithacus rubecula & $0.460(0.000)$ & $0.341(0.001)$ & $0.244(0.002)$ & $0.249(0.000)$ & $-0.054(0.098)$ & 0.46 \\
\hline Fringilla coelebs & $0.766(0.000)$ & & & $0.414(0.000)$ & & 0.63 \\
\hline Lophophanes cristatus & $0.499(0.000)$ & $0.283(0.005)$ & $0.203(0.025)$ & $0.270(0.000)$ & $-0.045(0.177)$ & 0.44 \\
\hline Oenanthe oenanthe & $-0.298(0.001)$ & & & $-0.161(0.003)$ & & 0.19 \\
\hline Periparus ater & $0.704(0.000)$ & $0.291(0.000)$ & $0.162(0.008)$ & $0.381(0.000)$ & $-0.046(0.086)$ & 0.68 \\
\hline Phylloscupus collybita & $0.328(0.005)$ & & & $0.178(0.006)$ & & 0.17 \\
\hline Poecile montanus & $0.451(0.000)$ & $-0.265(0.004)$ & & $0.244(0.000)$ & $0.042(0.095)$ & 0.29 \\
\hline Prunella modularis & $0.482(0.000)$ & $-0.164(0.051)$ & & $0.261(0.000)$ & $0.026(0.167)$ & 0.34 \\
\hline Pyrrhula pyrrhula & $0.440(0.000)$ & $0.267(0.000)$ & $0.132(0.069)$ & $0.238(0.000)$ & $-0.042(0.088)$ & 0.31 \\
\hline Regulus regulus & $0.301(0.000)$ & $0.449(0.000)$ & $0.289(0.002)$ & $0.163(0.000)$ & $-0.029(0.071)$ & 0.41 \\
\hline Sylvia atricapilla & $0.309(0.005)$ & & $0.187(0.096)$ & $0.167(0.004)$ & & 0.21 \\
\hline Turdus torquatos & & $-0.332(0.007)$ & & & $0.053(0.123)$ & 0.13 \\
\hline Turdus viscivorus & $0.199(0.058)$ & & $0.186(0.029)$ & $0.107(0.060)$ & & 0.11 \\
\hline
\end{tabular}


